\title{
TURBO-ROUNDABOUTS ALONG CORRIDORS: ANALYSIS OF OPERATIONAL AND ENVIRONMENTAL IMPACTS
}

Paulo Fernandes, MSc.

Graduate Student, Mechanical Engineering

University of Aveiro

Dept. Mechanical Engineering / Centre for Mechanical Technology and Automation (TEMA)

Campus Universitário de Santiago, 3810-193 Aveiro - Portugal

Phone: (+351) 234378 172, E-mail: paulo.fernandes@ua.pt

(Corresponding author)

Nagui M. Rouphail, PhD.

Director, Institute for Transportation Research and Education

North Carolina State University

NCSU Campus Box 8601, Raleigh, NC 27695-8601

Phone: (919) 515-1154, E-mail: rouphail@ncsu.edu

Margarida C. Coelho, PhD.

Assistant Professor, Mechanical Engineering

University of Aveiro

Dept. Mechanical Engineering / Centre for Mechanical Technology and Automation (TEMA)

Campus Universitário de Santiago, 3810-193 Aveiro - Portugal

Phone: (+351) 234378 172, E-mail: margarida.coelho@ua.pt 


\begin{abstract}
The number of turbo-roundabouts constructed in Europe has grown steadily in the past decade. While there has been extensive work on the operational and environmental impacts of isolated turbo-roundabouts, research on closely-spaced turbo-roundabouts along corridors is somewhat lacking.

The objective of this research is to evaluate the impact of turbo-roundabout corridors on both traffic performance and emissions. The research has three major thrusts: 1) to identify the hotspot emission locations along turbo-roundabout corridors; 2) to compare the overall performance of turbo-roundabout corridors against conventional two-lane roundabouts on arterials; 3 ) to address the integrated effect of geometric and operational characteristics of turboroundabout corridors on carbon dioxide, carbon monoxide, nitrogen oxides and hydrocarbons emissions.

Vehicle activity along with traffic flow data were collected from three turbo-roundabout corridors in the Netherlands. Site-specific operations were analyzed using microscopic traffic and emissions platforms (respectively, VISSIM and Vehicle Specific Power - VSP).

The results showed that emission hotspots along these corridors occurred in the segments located just downstream of the turbo-roundabout, both in absolute terms (more than $30 \%$ of total emissions) and per unit distance. It was also found that the implementation of two-lane roundabout corridors outperformed the turbo-roundabout corridors in terms of vehicle emissions, however the differences were not statistically significant ( $p$-value $<0.05)$. Data analysis indicated that an additional decrease in corridor's emissions (4-11\%, depending on the pollutant) may be reached by altering the spacing (from 180 to $240 \mathrm{~m}$ ) between two-closely spaced turboroundabouts.
\end{abstract}

Keywords: Emissions, Spacing, Traffic performance, Turbo-roundabout corridors 


\section{INTRODUCTION AND OBJECTIVES}

Turbo-roundabouts implementation as a traffic control at intersections has been steadily increasing in the past decade. This layout represents an innovative arrangement of conventional multi-lane roundabout that has altered intersection design in some European countries (1).

Turbo-roundabouts were first developed as a means to deal with some operational issues concerning two-lane roundabouts, namely the occurrence of unwanted weaving movements due to lane changing between outer and inner circulating lanes in this layout. An important benefit of turbo-roundabouts is therefore a reduction in the number of conflict points due to continuous spiral circuits, physically delineated by raised curbs at the entry, circulating and exit areas (2). FIGURE 1 depicts a conventional four-leg two-lane roundabout and a Basic turbo-roundabout of similar size.

\section{FIGURE 1 Differences between roundabout layouts: a) Conventional Two-lane roundabout; b) Basic Turbo-roundabout (3) [Source https://www.google.pt/maps].}

The main differences between layouts are as follows (2):

1. On a conventional roundabout, the outer circulatory lane at the major entrances ( 1 and 3 ) is used by a fraction of the through movements; on a turbo-roundabout, the opposing traffic is concentrated in a single-lane;

2. On a conventional roundabout, drivers in the right lane of the minor entrances ( 2 and 4) are affected by all circulating vehicles; on a turbo-roundabout, the outer entry lane is used only for right-turning (2-3 and 4-1 movements), and the opposing traffic is reduced since a proportion of the through traffic is physically separated at the exit;

3. On a conventional roundabout, right-turning traffic must use the right entry lane (2-3 and 4-1 movements); on a turbo-roundabout, drivers at the minor entrances can use both the left and right entry lanes.

There is significant literature on the operational (4-11) and environmental $(3 ; 12)$ evaluation of isolated turbo-roundabouts. However, research on the performance of series of interdependent turbo-roundabouts along an arterial is scarce. The notion of moving platoons of vehicles to maximize the performance efficiency is not applicable to roundabouts or turbo-roundabouts because gap acceptance principles allow more dispersed flows to mingle (13).

There are several unanswered questions about the operational characteristics and environmental benefits of turbo-roundabout corridors. If vehicles at a downstream turboroundabout are mostly turning left, and simultaneously the mid-block of an upstream turboroundabout is congested, corridor's performance may be considerably worse than an equivalent two-lane roundabout corridor. This is because drivers at a turbo-roundabout have less flexibility to select the entry lane, which allows a smaller range of traffic splits before congestion occurs. Moreover, the impacts on queues and emissions may be more sensitive for very short spacing between adjacent turbo-roundabouts, and could suggest a different traffic control for a given intersection along the corridor.

The objective for this study is to quantify and contrast traffic performance and emissions in the context of turbo-roundabout corridors. The overall performance of corridor with turboroundabouts is hypothesized to be inferior to that of an equivalent conventional two-lane roundabout corridor. 
This research investigates the above concerns at real-world turbo-roundabout corridors that experience variations in traffic flow and directional splits at each entry. The study also includes a performance assessment of closely-spaced turbo-roundabouts. In summary, the major components of the research include:

1. Identifying hotspot emission locations at turbo-roundabout corridors with variations in spacing, traffic flow and directional splits distributions;

2. Assessing the collected field data and comparing the performance of turboroundabout corridors relative to equivalent two-lane roundabout corridors;

3. Improving the corridor environmental performance by proposing changes to some operational and geometric variables.

\section{LITERATURE REVIEW}

The capacity, safety and emissions at isolated turbo-roundabouts is well researched, and methods to compare their performance with conventional roundabouts are well established. Safety benefits of turbo-roundabouts are recognized in most previous works $(2 ; 11 ; 12 ; 14)$, however, the literature review indicates a dearth of knowledge about the capacity and environmental benefits of turbo-roundabouts while operating in corridors.

Early studies carried out on turbo-roundabout capacity have shown an increased capacity compared with that of conventional roundabouts of similar size (4-6). Nevertheless, site-traffic conditions and geometric layouts tend to influence the overall performance of turbo-roundabouts $(7 ; 11)$. Corriere and Guerrieri $(8)$ explain that each approach capacity at turbo-roundabouts depends on lane capacity, conflicting traffic flows, pedestrian activity, driving habits and the balance of traffic demand on each approach. Vasconcelos et al. (12) stated that turbo-roundabout can only reach comparable capacity levels to the traditional two-lane layout when the proportion of right-turning traffic is unusually high $(>60 \%)$. On the other hand, Lambertus et al. (9) highlighted the fact that compact German two-lane roundabouts yielded lower capacity levels than Dutch turbo-roundabouts because of better use of inner circulating lane in the latter layout.

In a recent study on emissions at roundabouts by Vasconcelos et al. (12), turboroundabout was found to be deficient in reducing carbon dioxide $\left(\mathrm{CO}_{2}\right)$ and nitrogen oxides $\left(\mathrm{NO}_{\mathrm{X}}\right)$ emissions when compared with a two-lane roundabout, although it reduced other local pollutants (carbon monoxide - $\mathrm{CO}$ and hydrocarbons - HC). Fernandes et al. (3) confirmed that vehicles driving through turbo-roundabouts generated more emissions (15-22\%, depending on the pollutant) compared with multi-lane roundabouts.

Some local authorities in the United States (US) have recently proposed and constructed several conventional roundabout corridors (13). In this context, interest also is growing about the turbo-roundabout concept in the US (15), but little research has addressed objectively the efficacy of series of turbo-roundabouts on an arterial. Silva et al. (16) compared traffic performance, fuel use, and pollutant emissions at turbo and two-lane roundabouts corridors. They found that the turbo-roundabout corridor was ineffective after reaching saturation, especially in terms of traffic performance. However, the aforementioned research had three limitations: 1) the corridor did not include closely-spaced intersections; 2) vehicle dynamic data were only collected from conventional roundabouts (16); and 3) only one site was evaluated, which does not allow transferability of the findings to other corridors.

From the facts presented above, two main research gaps are revealed: 1) none of previous studies assessed the situations of overlapping influence areas between adjacent turbo- 
roundabouts or short upstream-downstream segments at either end of the turbo-roundabout; and 2) little attention was given to the impact of the geometric characteristics of turbo-roundabout corridor on measured or estimated vehicle emissions.

\section{METHODOLOGY}

The methodology involved a combination of empirical data analysis and microsimulation.

First, the analyst collected vehicle dynamic data (second-by-second speed and acceleration-deceleration), and measurements of overall congestion levels at several turboroundabout corridors. Each corridor was then sub-divided into several sub-segments. The Vehicle Specific Power (VSP) methodology (17) was used to estimate $\mathrm{CO}_{2}, \mathrm{CO}, \mathrm{NO}_{\mathrm{x}}$ and $\mathrm{HC}$ emissions, with the intent to identify the hotspot emission locations.

Subsequent to the field work, each corridor was coded in the VISSIM traffic model (18), and then calibrated according to the site-specific characteristics. Vehicle Specific Power (VSP) (17) and EMEP/EEA (19) methodologies were paired with VISSIM to compare emissions, energy and traffic performance measures between these corridors and equivalent two-lane roundabout corridors.

\subsection{Segments and sub-segments definitions}

The analysis corridor was divided into different sub-segments to quantify emissions impacts. This level of segmentation is based on changes in speeds as drivers decelerate while approaching the turbo-roundabout, negotiate the corresponding circulating lane and accelerate while leaving the turbo-roundabout back to cruise speed.

The research team defined a segment from the downstream exit lane from one turboroundabout to the upstream yield lane of the next roundabout in the direction of travelling. FIGURE 2 shows the suggested segmentation along a corridor with two pairs of turboroundabouts TR1/TR2 and TR2/TR3, separated by Segments A and B, respectively. Based on vehicle activity data, each segment is comprised by different sub-segments:

- Circulating Area: Vehicle decelerates to negotiate traffic in the circulating area of turbo-roundabout and then accelerates while exiting the turbo-roundabout (deceleration followed by an acceleration pattern);

- Downstream: Vehicle accelerates after exiting the turbo-roundabout back to cruise speed (acceleration only);

- Mid-block: Vehicle operates near the cruise speed with slight acceleration or deceleration rates (constant speed);

- Upstream: Vehicle begins to decelerate while approaching the downstream turboroundabout (deceleration only).

\section{FIGURE 2 Segments and sub-segments definition for a corridor with turbo-roundabouts [Source https://www.google.pt/maps].}

An influence area must be defined to estimate the length of roadway upstream and downstream of a turbo-roundabout over which speeds are reduced due to the presence of the turboroundabout (13). To be consistent with the Highway Capacity Manual procedure (20), the downstream, midblock and upstream sub-segments are assumed to be equal in length. 


\subsection{Study sites identification}

To account for applicability and variability in real-world turbo-roundabout layouts, three corridors in the Netherlands (N1, N2, and N3) were selected. The dataset includes 10 turboroundabouts, and 20 downstream and upstream sub-segments (considering both directions of travel). The candidate sites have a similar overall corridor length but vary in spacing between roundabouts (ranging from $180 \mathrm{~m}$ to $650 \mathrm{~m}$ ) with approach speed limits mostly below $45 \mathrm{~km} / \mathrm{h}$. The first site (N1) is near a commercial area and is located $10 \mathrm{~km}$ southeast of Gouda. Approximately $7 \%$ of N1 traffic is composed of Heavy-Duty Vehicles (HDV) and about $30 \%$ of movements at TR2 (southeast-northwest) and TR3 (southeast-northwest) are left-turning. The second site (N2) is near an urban area and includes a turbo-roundabout interchanges (TR3). This corridor primarily serves through traffic (eastbound and westbound). Finally, N3 site has twobridge turbo-roundabout interchanges (TR3 and TR4) and is near the urban area of Leiden. Some entries of TR2 and TR3 along N3 have moderate percentage of right-turning. N3 also has one pair of turbo-roundabouts (TR1/TR2) located in close proximity to each other ( $\sim 180 \mathrm{~m})$, and therefore make the case for overlapping turbo-roundabouts influence areas.

TABLE 4 summarizes the relevant information of each site including layout, GPS coordinates, traffic flows, spacing between adjacent turbo-roundabouts (measured from the downstream exit lane from one turbo-roundabout to the upstream yield lane of the adjacent turbo-roundabout in the direction of travel) and length of corridor.

\section{TABLE 1 Summary of Study Site Characteristics}

\subsection{Field data collection}

In this section, the main steps of the monitoring plan are enumerated. Before proceeding with the data collection, the authors identified the relevant data for assessing corridor's performance. The types of data of interest are:

$\underline{\text { Site-specific data }}$

- Posted speed limit;

- Turbo-roundabout geometry and spacing.

Time dependent flow data

- Entry and circulating traffic flows;

- Directional split of traffic;

- Vehicle dynamic data (speed and acceleration-deceleration on a second-by-second basis).

The research team scouted and collected these data at the selected study cases during the afternoon period (4-6 p.m.) on three typical weekdays (Tuesday to Thursday). Traffic volumes were gathered from one overhead video and a smartphone in 5-min time intervals. Equipped light duty vehicle performed several trips at the corridor level (mainly through movements).

A GPS data logger and an Onboard Diagnostic Reader (OBD) sensor were installed in a test-vehicle to record vehicle speed, distance travelled, and deceleration-acceleration rates in 1second interval. A male driver of age 30 with more than 10 years of driving performed several runs during off-peak, morning, and evening periods (from 8 a.m. to 6 p.m.) in May 2016. These runs were conducted with different driving types (calm, intermediate and aggressive) to take into account different traffic conditions. 
The sample size (number of runs) for vehicle dynamic data collection and videotaping was evaluated using the Modified Method proposed by Li et al. (22). Thus, total data collected included 315 GPS travel runs ( $\approx 105$ per site), which corresponded to a road coverage of $500 \mathrm{~km}$, and $4 \mathrm{~h}$ of video data at each location (48 data samples of $15 \mathrm{~min}$ ).

\subsection{Emissions estimation}

Frey et al. (17) introduced a "modal binning approach" for calculating vehicular emissions based on the Vehicle Specific Power (VSP). VSP takes into account engine power demand associated with changes in vehicle potential and kinetic energies, aerodynamic drag, and rolling resistance $(17 ; 23)$.

VSP values are categorized into 14 modes, and an emission factor for each mode is used to estimate the footprints of $\mathrm{CO}_{2}, \mathrm{CO}, \mathrm{NO}_{\mathrm{X}}$ and $\mathrm{HC}$ emissions for different vehicles types such as Gasoline Passenger Vehicles (GPV) (24), Diesel Passenger Vehicles (DPV) (25), Light Duty Diesel Trucks (LDDT) (25), and Hybrid Electric Vehicles (HEV) (26). These values are the average of tailpipe emissions measured by Portable Emissions Measurement Systems (PEMS) (17).

This research initially focused on emissions along individual sub-segments of turboroundabout corridors based on field data. Thus, $\mathrm{CO}_{2}, \mathrm{CO}, \mathrm{NO}$, and $\mathrm{HC}$ modal rates were weighted by the amount of time spent in each VSP mode for a given speed profile.

\subsection{Microsimulation platform for traffic and emissions}

\subsubsection{Traffic and emissions modelling}

The microscopic traffic model VISSIM 5.3 was used to simulate traffic operations (18). All simulation experiments were made for the analysis period between 4:30 p.m. and 6:00 p.m. with a 30-min "warm-up" period prior to 5:00 p.m. to load the study domain adequately with corresponding traffic flow.

Network links coding was made following good practices for roundabouts (27) in which the number of links to represent the intersection was equal to the number of entry and exit legs, and considering the contribution of each entering, circulating and exiting lanes. Several links were coded in the turbo-roundabout influence areas to fulfill reproduce speed profiles as vehicles driving through turbo-roundabouts. Lastly, traffic flows were assigned for each link and according the intersection-specific split distributions and then GPS traces were matched to each coded link.

Emissions estimates using VSP methodology were based on vehicle dynamics data (speed and acceleration-deceleration) gathered from the VISSIM traffic model calibrated with GPS and OBD data (Section 3.5.2). A console application in C\# programming language was developed to compute second-by-second vehicle dynamics data from VISSIM output.

The research team fit as much as possible the emission rates to the Dutch fleet, namely engine capacity, average fleet age and fuel type $(12 ; 25)$. For all sites, the following fleet composition was used (28; 29): 70\% of GPV, $15 \%$ of DPV, $6 \%$ of HEV and 9\% of LDDT.

Additionally, the EMEP/EEA method was used to estimate HDV emissions (19) at site N1. Emission factors for diesel heavy-duty vehicles from Euro 1 to Euro VI emission standards are calculated as a function of the average speed. The generic functions and the values for the coefficients for these equations can be found elsewhere (19). The emissions' factors depend on 
the engine capacity and age of each vehicle class and fuel type. For other sites, HDV were excluded from the analysis since they represented less than $2 \%$ of the traffic composition.

\subsubsection{Model Calibration and Validation}

The traffic model was calibrated and validated using the empirical data collected from turboroundabout corridors during evening peak period (from 4 p.m. to 6 p.m.). The procedure was conducted separately by site and using different data sets for calibration $(\approx 80 \%)$ and validation $(\approx 20 \%)$.

VISSIM model was first calibrated by modifying driver behavior and vehicle performance parameters, and by assessing their impact on traffic flows and speeds by coded link. The following parameters were calibrated: car-following, lane-change, gap acceptance parameters, and simulation resolution (18). For each site, the calibration proceeded in three steps:

$1^{\text {st }}$ ) Using default values of car-following, lane-change, gap acceptance parameters, and simulation resolution, the observed and simulated traffic flow and speeds were compared;

$2^{\text {nd }}$ ) These parameters were optimized by using Simultaneous Perturbation Stochastic Approximation (SPSA) algorithm in which the objective function was the minimization of Normalized Root Mean Square (NRMS) (30);

$3^{\text {rd }}$ ) Optimization was stopped after complying the following calibration target - at least $85 \%$ of all links must meet the criteria of GEH (acronym for Geoffrey E. Havers) < 4 (31).

The model validation addressed how well the simulated travel time and accelerations matched the field data. Observed and simulated accelerations were computed by coded link.

\subsection{Simulated Scenarios}

The baseline scenario represents well-calibrated turbo-roundabout corridors with the observed traffic flows at N1, N2 and N3 that had been used to calibrate the traffic model. After that, curb raised dividers are removed, and inner circle of each one of the turbo-roundabouts is reshaped to the final conventional two-lane layout according to Dutch design (32). The number of approach lanes on the major and minor roads was assumed the same as in the baseline scenario.

\section{RESULTS AND DISCUSSION}

In this section, the main results from the empirical data are analyzed followed by the simulation calibration and validation, and experiments.

\subsection{Segments emissions}

This section uses the collected data to estimate vehicular emissions at each specified segment using VSP methodology. Emissions per vehicle and per kilometer by segment are presented in TABLE 2. The results indicate that:

- The highest amounts of $\mathrm{CO}_{2}, \mathrm{CO}, \mathrm{NO}$ and $\mathrm{HC}$ emissions per vehicle (nearly $35 \%$, $38 \%, 40 \%$ and $33 \%$, respectively) in $\mathrm{N} 1$ corridor were recorded downstream. This segment corresponds to about $25 \%$ of travel distance across the corridor. In contrast, circulating areas had a moderate impact on emissions (overall contribution on total emissions was less than 22\%). This was mostly due to low speeds and smooth acceleration-deceleration rates at the circulatory ring of turbo-roundabouts; 
- Downstream segments generated the highest amount of emissions per kilometer travelled across N1. For example, $\mathrm{NO}_{\mathrm{X}}$ emissions per unit distance were $69 \%$ higher than the average values for the entire corridor. Circulating areas also reached emissions per kilometer higher than average $\mathrm{N} 1$ values, especially for $\mathrm{CO}_{2}(20 \%$ higher than the average $\mathrm{CO}_{2}$ value);

- The results from N2 corridor showed an identical trend. Downstream segments accounted for $41 \%$ of $\mathrm{CO}_{2}$ emissions, while covering $28 \%$ of travel distance. Because turbo-roundabouts are generously spaced, vehicles attained cruise speeds at midblock. Specifically, these sub-segments contributed to more than $26 \%$ of total emissions;

- Emissions per unit distance along the downstream sub-segments (ranged from $19 \%$ to $63 \%$ for $\mathrm{HC}$ and $\mathrm{NO}_{\mathrm{X}}$ ) and circulating areas (ranged from $14 \%$ to $30 \%$ for $\mathrm{NO}_{\mathrm{X}}$ and $\mathrm{HC}$ ) were higher than the average N2 corridor value. Interestingly, emissions per kilometer at the mid-block were lower than the average corridor value $(\sim 23 \%)$. This is explained by the presence of smooth speed profiles;

- Downstream segments had a major impact on emissions across the N3 site. Vehicles emitted about $34 \%$ and $35 \%$ of $\mathrm{CO}_{2}$ and $\mathrm{CO}$ emissions, respectively, in $23 \%$ of travel distance. Similarly, circulating areas and mid-block segments also had a major impact on emissions ( $26 \%$ of total emissions);

- Hotspot emission locations (by unit distance) at the N3 site were found at downstream segments. This was particularly true for $\mathrm{NO}_{\mathrm{X}}$ emissions $(48 \%$ higher than the average corridor value).

\section{TABLE 2 Emissions per vehicle and per kilometer by segment across turbo-roundabout corridor}

It must be emphasized that the impact of downstream might be also observed in other traffic control treatments such as signalized and stop-controlled intersections. However, this phenomenon only occurs when vehicles makes a complete stop at the intersection. On a circular intersection, the acceleration episodes always occur even though vehicles do not make a stop on the approach.

In summary, vehicles at the downstream sub-segments generated the highest emissions levels both in absolute terms and per kilometer. Significant emissions (by unit distance) were also observed in circulating areas at the N3 site (23\% higher than the average corridor value) where average spacing was the lowest among corridors (see TABLE 4 for those details). This suggests that the spacing may influence acceleration-deceleration profiles, and therefore the spatial distribution of emissions.

The spacing values (considering both directions of travel) were plotted against the global and local pollutant emissions per kilometer by segment. The estimated regression models (using power functions) confirmed the prior premises, as shown in FIGURE 3. For these models, the analysis of $R^{2}$ ( $F$-test) and the analysis of coefficients for the model ( $T$-test) resulted in $p$-values lower than 0.001. The statistical correlations between spacing and $\mathrm{CO}_{2}, \mathrm{CO}, \mathrm{NO}$ and $\mathrm{HC}$ were $R^{2}=0.87,0.74,0.80$ and 0.85 , respectively. The scattered graphs showed that for low spacing values $(<200 \mathrm{~m})$, the emissions were approximately $30 \%$ higher than those observed for moderate spacing values $(\sim 350 \mathrm{~m})$. These findings are in line with previous research conducted in conventional single-lane and multi-lane roundabouts corridors in the US (33). 


\section{FIGURE 3 Emissions per kilometer versus spacing: a) $\mathrm{CO}_{2}$; b) $\mathrm{CO}$; c) $\mathrm{NO}$; d) $\mathrm{HC}$.}

\subsection{Simulation Model Experiments and Results}

\subsubsection{Model Calibration and Validation}

Summary statistics of the VISSIM calibrated model parameters at the candidate sites are exhibited in FIGURE 4. The graphs also include the corresponding values for car following and gap acceptance parameters. The variation in lane change parameters did not affect NRSM and GEH values. This is mostly corridors operate above capacity and therefore vehicles with a predefined route choice are not retained before curb raised dividers at the turbo-roundabouts approaches. The existing two-lane segments also have short lengths that allow few overtaking maneuvers. A simulation resolution of 10 time steps per simulation seconds was used in all sites to fit the time resolution of traffic and emissions models (a second-by-second basis).

The results demonstrated a very good fit between simulated and observed data using a linear regression analysis. The predicted $R^{2}$ were higher than 0.90 for simulated traffic flows (FIGURE 4-a, d, g) and speeds (FIGURE 4-b, e, h) using site-calibrated values. In turn, more than $90 \%$ of the coded links (between 62 and 73 links, depending on the site) yielded a GEH value lower than 4 , thereby satisfying the calibration criteria (31).

For validation, the comparison of observed and simulated travel time was conducted using a different data set from the calibration and additional 15 random seed runs, as suggested elsewhere (34). SPSS software was used to perform the statistical analysis. The maximum average percent travel time differences [using 30 floating car runs (31) by through movement] were observed in the N1 site on the southeast-northwest direction $(\sim 6 \%)$. This is explained by the high traffic demand on that site that led to travel time variability. However, the difference between observed and simulated travel time was not statistically significant ( $p$-value $>0.05$ ) on all routes. The corresponding acceleration and deceleration values (FIGURE 4-c, f, i) also confirmed a good correspondence of the modeling platform. Using the calibrated VISSIM parameters, linear trend lines matched the acceleration data with correlation coefficients ranged from 0.67 to 0.69 for $\mathrm{N} 1$ and $\mathrm{N} 3$ sites.

FIGURE 4 Observed versus Simulated parameters using calibrated model: a) N1-Volumes; b) N1-Speed; c) N1- Acceleration-Deceleration; d) N2-Volumes; e) N2-Speed; f) N2Acceleration-Deceleration; g) N3-Volumes; h) N3- Speed; i) N3- Acceleration-Deceleration.

\subsubsection{Comparing Turbo and Conventional Roundabout Emissions and Traffic Performance This section compares the VISSIM simulated vehicular emissions and traffic performance measures of turbo-roundabout corridors and proposed conventional two-lane roundabout corridors.}

When N1 corridor is considered, no differences between two-lane and turbo-roundabout corridors were observed (TABLE 3). The corridor with conventional roundabouts had average emissions reductions of about $1 \%$, and approximately $2 \%$ lower travel time. However, turboroundabout corridor yielded fewer stop-and-go situations ( 4\%) when compared to the two-lane layout. This is mostly explained by the fact that vehicles in the right entry lane of TR2 on the minor entries are affected by the fraction of the opposing traffic since two circulating lanes are available for through traffic. Yet vehicles spent more time driving along turbo-roundabout 
corridor compared to two-lane layout (caused by slow approach and circulating speeds as a result of using curb raised dividers at the turbo-roundabouts).

The differences in both layouts at the N2 site were more pronounced than in the N1 case. Corridor with two-lane roundabouts yielded the highest emissions reductions in $\mathrm{CO}_{2}$ and $\mathrm{HC}$ at $3 \%$ and $4 \%$, respectively, and it performed well concerning the traffic performance outputs (its implementation allowed the number of stops to be reduced by 14\%). This happens because some turbo-roundabouts along N2 (TR1/TR2) have one dedicated lane for through traffic and moderate left-turning movement which leads to a drop in capacity.

Considering site $\mathrm{N} 3$, the results revealed small differences between the conventional and turbo-roundabout layouts $\left(\mathrm{CO}_{2}, \mathrm{CO}\right.$ and $\mathrm{HC}$ decreased $1 \%, 1 \%$ and $4 \%$ respectively with the proposed corridor while idling situations were reduced by more than $4 \%$ ). The relative good performance of turbo-roundabout corridor at the N3 occurred for two main reasons: 1) moderate proportion of right-turning traffic in some main entries; 2) almost turbo-roundabouts have two lanes for through traffic.

\section{TABLE 3 Emissions and traffic performance parameters (with standard error of the mean) per scenario}

The overall analysis showed that the differences in the average emissions between layouts ranged from $1 \%$ to $4 \%$ between $\mathrm{N} 1$ and N3 sites. In such cases, the difference in global and local pollutant emissions between turbo and conventional roundabout was not statistically significant at the $5 \%$ significance level.

Despite these results, it is not clear if turbo-roundabouts will perform efficiently under high-congestion flows. The impact of spacing on emissions had been demonstrated previously, and therefore the optimal placement of turbo-roundabouts could bring additional traffic benefits.

\subsection{Impact of corridor geometric and operational characteristics}

This section evaluated the emission impacts of varying the spacing values between adjacent turbo-roundabouts at the N3 site. Two motivations supported the choice of N3 in this analysis: 1) low average spacing; and 2) moderate traffic flow at the minor entries.

Four hypothetical spacing values between TR1 and TR2 were applied, assuming that TR2 was moved along the mid-block sub-segment. These were $120 \mathrm{~m}, 180 \mathrm{~m}$ (current spacing), 240 $\mathrm{m}$ and $300 \mathrm{~m}$. For each spacing value, five traffic scenarios were defined: observed traffic flow (D1); expected traffic growth of 20\% (D2), $40 \%$ (D3) and 60\% (D4); and directional splits of 3070 at the TR2 entrances, in which each set of values indicates the percentages of right-turning and through traffic movements, respectively (D5).

FIGURE 5 displays the effect of varying the spacing between TR1 and TR2 at the above scenarios on $\mathrm{CO}_{2}, \mathrm{CO}, \mathrm{NO}$ and $\mathrm{HC}$ emissions. Some conclusions are:

- No significant differences in emissions were found among spacing values with traffic demand levels of D1, D2 and D3;

- Vehicles generated the lowest $\mathrm{CO}_{2}$ emissions per kilometer by adopting a $240 \mathrm{~m}$ of spacing between TR1 and TR2 regardless of traffic scenarios (D1-D5);

- Emissions increased markedly near saturation (D4) at low-spacing values (120 m and $180 \mathrm{~m}$ ). For instance, if one adopted a spacing solution of $240 \mathrm{~m}$, then one could save 
up to $8 \%, 4 \%, 5 \%$ and $11 \%$ in $\mathrm{CO}_{2}, \mathrm{CO}, \mathrm{NO}_{\mathrm{X}}$ and $\mathrm{HC}$ emissions, respectively when compared to the existing spacing;

- Under uncongested conditions (D1-D3), the current spacing between TR1 and TR2 was a particularly effective means to reduce local pollutant emissions. This occurred because vehicles attained higher speeds at the mid-block section between TR1 and TR2 when the spacing was $240 \mathrm{~m}$, and therefore they had sharper acceleration and deceleration rates;

- Locating TR2 farther from TR1 (300 $\mathrm{m}$ of spacing) negatively affected emissions upstream of TR3. There were increases in emissions of about $4 \%$ for $\mathrm{CO}$ and $\mathrm{NO}_{\mathrm{X}}$ compared with that of the existing conditions (180 $\mathrm{m}$ and D1);

- The emissions per unit distance increased when $70 \%$ of vehicles at TR2 went through (D5). This was particularly true in highest spacing between TR1 and TR2 (3\% more $\mathrm{CO}$ and $\mathrm{NO}_{\mathrm{X}}$ than those obtained with the existing spacing).

The change in spacing can be impossible in practical terms in many corridors due to site-specific land use constraints. Rather than changing spacing, this section stressed the importance of analyzing the location of adjacent turbo-roundabouts (prior their construction or in existing facilities) to avoid high traffic congestion or pollutant emission levels.

\section{FIGURE 5 Emission trends with demand and spacing scenarios: a) $\mathrm{CO}_{2}$ per kilometer; b) CO per kilometer; c) NOx per kilometer; d) HC per kilometer.}

\section{CONCLUSIONS}

This paper explored the impact of turbo-roundabout corridors on traffic performance and vehicular emissions. Traffic flow along with vehicle dynamic data were collected from three real-world turbo-roundabout corridors in the Netherlands.

The study first introduced a methodology to quantify the hotspot emission locations for these interdependent turbo-roundabouts based on empirical data. The downstream (acceleration) sub-segments were identified as the emission hotspots both in absolute terms (overall contribution on emissions exceeded $30 \%$ ) and per unit distance.

The evaluation of global and local pollutants emissions for different values of spacing demonstrated the influence of this parameter on the spatial distribution of emissions along turboroundabout corridors $\left(R^{2}>0.70\right)$.

The consequences of comparing existing turbo-roundabout corridors to equivalent twolane roundabout corridors were further carried out in a simulation environment. This study used the VSP and EMEP/EEA methodologies, which takes into account speed trajectories from the VISSIM traffic model, to estimate the emissions generated from vehicles. The results showed that vehicles through the turbo-roundabout corridors had on average higher travel time than under the two-lane roundabout corridors. Nevertheless, the environmental benefits of converting turbo-roundabout into two-lane roundabouts in two sites was not statistically significant at $p$ value $<0.05$. This was mostly due to the fact that some turbo-roundabouts had two lanes available for through traffic over the entire corridor.

However, when the demand reached saturation, closely spaced turbo-roundabouts (spacing <180 m) resulted in a marked increase in overall corridor emissions. For instance, an additional decrease of emissions between 4\%-11\% (depending on the pollutant) may be expected by adopting a spacing of $240 \mathrm{~m}$ when compared to a spacing of $180 \mathrm{~m}$. 
Thus, it is clear that the implementation of series of turbo-roundabouts along corridors as an alternative to traditional two-lane roundabout corridors results in small increases in emissions and traffic performance parameters in almost sites. It should also be mentioned that the safety benefits of turbo-roundabouts are well recognized, which makes them a feasible solution to be implemented in other European countries and in the US.

The use of turbo-roundabouts along arterials requires a further analysis prior to their construction. This is especially important when site-specific operational (high-traffic levels or high proportion of left-turning) or geometric (land use constraints that result in short spacing) concerns are presented.

Future work must be conducted to study the possibility of replacing turbo-roundabouts on an existing corridor by other turbo-roundabout layouts, and assess their impact on traffic performance and vehicular emissions.

\section{ACKOWLEDGEMENTS}

This work was partially funded by the Strategic Project UID-EMS-00481-2013. P. Fernandes acknowledges the support of the Portuguese Science and Technology Foundation (FCT) Scholarship SFRH/BD/87402/2012. The authors also acknowledge to the project PTDC/EMSTRA/0383/2014, that was funded within the project 9471-Reiforcement of RIDTI and funded by FEDER funds.

\section{REFERENCES}

[1] Tollazzi, T. Alternative Types of Roundabouts: An Informational Guide. Springer International Publishing, Cham (ZG), Switzerland, 2014.

[2] Fortuijn, L. Turbo Roundabouts: Estimation of the capacity. Transportation Research Record: Journal of the Transportation Research Board, Vol. 2096, 2009, pp. 16-24.

[3] Fernandes, P., S. R. Pereira, J. M. Bandeira, L. Vasconcelos, A. B. Silva, and M. C. Coelho. Driving around turbo-roundabouts vs. conventional roundabouts: are there advantages on pollutant emissions? International Journal of Sustainable Transportation, Vol. 10, No. 9, 2016, pp. 846-860.

[4] Yperman, I., and L. H. Immers. Capacity of a turbo-roundabout determined by microsimulation, Presented at 10th World Congress on ITS, Madrid, Spain, 2003.

[5] Engelsman, J. C., and M. Uken. Turbo roundabouts as an alternative to two lane roundabouts, Presented at 26th Annual Southern African Transport Conference, Pretoria, South Africa, 2007.

[6] Brilon, W. Turbo Roundabouts - An Experience from Germany. Presented at 2nd Roundabout Conference, Transportation Research Board, Kansas City, MO, 2008. [7] Giuffrè, O., M. Guerrieri, and A. Granà. Evaluating capacity and efficiency of turboroundabouts. Presented at 88th Annual Meeting of the Transportation Research Board, Washington, DC, 2009.

[8] Corriere, F., and M. Guerrieri. Performance Analysis of Basic Turbo-Roundabouts in Urban Context. Procedia - Social and Behavioral Sciences, Vol. 53, 2012, pp. 622-632.

[9] Lambertus, G., H. Fortuijn, and S. P. Hoogendoorn. Capacity Estimation on Turboroundabouts with Gap Acceptance and Flow Level Methods. Transportation Research Record: Journal of the Transportation Research Board, Vol. 2517, 2015, pp. 71-79. [10] Giuffrè, O., A. Granà, and S. Marino. Turbo-roundabouts vs Roundabouts Performance Level. Procedia - Social and Behavioral Sciences, Vol. 53, 2012, pp. 590-600. 
[11] Silva, A. B., L. Vasconcelos, and S. Santos. Moving from Conventional Roundabouts to Turbo-roundabouts. Procedia - Social and Behavioral Sciences, Vol. 111, 2014, pp. 137-146. [12] Vasconcelos, L., A. B. Silva, A. M. Seco, P. Fernandes, and M. C. Coelho.

Turboroundabouts: Multicriterion Assessment of Intersection Capacity, Safety, and Emissions. Transportation Research Record: Journal of the Transportation Research Board, Vol. 2402, 2014, pp. 28-37.

[13] Bugg, Z., B. Schroeder, P. Jenior, M. Brewer, and L. Rodegerdts. A Methodology to Compute Roundabout Corridor Travel Time, Presented at 94th Annual Meeting of the Transportation Research Board, Washington, DC, 2015.

[14] Fortuijn, L. Turbo Roundabouts: Design Principles and Safety Performance. Transportation Research Record: Journal of the Transportation Research Board, Vol. 2096, 2009, pp. 16-24.

[15] Trueblood, M. Retrofitting Closely Spaced Intersections Using the Peanut Turboroundabout Concept, Presented at 3rd International Conference on Roundabouts, Transportation Research Board, Carmel, Indiana, 2011.

[16] F. Santos, B., G. H.A. Correia, M. Kroesen, A. B. Silva, P. Mariano, and J. P. Silva. Performance Assessment of Turbo-roundabouts in Corridors. Transportation Research Procedia, Vol. 10, 2015, pp. 124-133.

[17] US EPA. Methodology for developing modal emission rates for EPA's multi-scale motor vehicle \& equipment emission system. Publication Prepared by North Carolina State University for US Environmental Protection Agency, EPA420, Ann Arbor, MI, 2002.

[18] PTV AG. VISSIM 5.30-05 User Manual. Planung Transport Verkehr AG, Karlsruhe, Germany, 2011.

[19] EEA. EMEP/EEA air pollutant emission inventory guidebook: Exhaust emissions from road transport. Publication European Environmental Agency, Technical report No 9/2009, 2013. [20] HCM. The Highway Capacity Manual. Transportation Research Board, Washington, DC, 2010.

[21] CROW. Turborotondes. In, Publicatie 257. Dutch Information and Technology Platform, Ede, Netherlands, 2008.

[22] Li, S., K. Zhu, B. v. Gelder, J. Nagle, and C. Tuttle. Reconsideration of Sample Size Requirements for Field Traffic Data Collection with Global Positioning System Devices.

Transportation Research Record: Journal of the Transportation Research Board, Vol. 1804, 2002, pp. 17-22.

[23] Kutz, M. Environmentally Conscious Transportation. John Wiley \& Sons, New York, US, 2008.

[24] Anya, A. R., N. M. Rouphail, H. C. Frey, and B. Liu. Method and Case Study for Quantifying Local Emissions Impacts of Transportation Improvement Project Involving Road Realignment and Conversion to Multilane Roundabout. Presented at 92nd Annual Meeting, Transportation Research Board, Washington, DC, 2013.

[25] Coelho, M. C., H. C. Frey, N. M. Rouphail, H. Zhai, and L. Pelkmans. Assessing methods for comparing emissions from gasoline and diesel light-duty vehicles based on microscale measurements. Transportation Research Part D: Transport and Environment, Vol. 14, No. 2, 2009, pp. 91-99.

[26] Zhai, H., H. Christopher Frey, and N. M. Rouphail. Development of a modal emissions model for a hybrid electric vehicle. Transportation Research Part D: Transport and Environment, Vol. 16, No. 6, 2011, pp. 444-450. 
[27] Fontes, T., S. R. Pereira, P. Fernandes, J. M. Bandeira, and M. C. Coelho. How to combine different microsimulation tools to assess the environmental impacts of road traffic? Lessons and directions. Transportation Research Part D: Transport and Environment, Vol. 34, 2015, pp. 293-306.

[28] EUROSTAT. Passenger cars in the EU. http://ec.europa.eu/eurostat/statisticsexplained/index.php/Passenger_cars_in_the_EU\#Further_Eurostat_information, Accessed January 21, 2016.

[29] CBS. Motor vehicle fleet by municipality. Centraal Bureau voor de Statistiek [In Dutch]. http://www.swov.nl/UK/Research/Cijfers/Cijfers_Achtergronden-UK.html, Accessed January 20, 2016.

[30] Paz, A., V. Molano, and A. Khan. Calibration of Micro-Simulation Traffic-Flow Models Considering All Parameters Simultaneously. Presented at 93rd Annual Meeting, Transportation Research Board, Washington, DC, 2014.

[31] Dowling, R., A., Skabadonis, and V. Alexiadis. Traffic analysis toolbox, volume III:

Guidelines for applying traffic microsimulation software. Publication FHWA-HRT-04-040, FHWA, U.S. Department of Transportation, 2004.

[32] Royal Haskoning DHV. Roundabouts - Application and design: A practical manual. Publication Ministry of Transport, Public Works and Water Management Partners for Roads, Amersfoort, The Netherlands, 2009.

[33] Fernandes, P., K. Salamati, N. M. Rouphail, and M. C. Coelho. Identification of emission hotspots in roundabouts corridors. Transportation Research Part D: Transport and Environment, Vol. 37, 2015, pp. 48-64.

[34] Hale, D. How many netsim runs are enough? McTrans, Vol. 11, No. 3, 1997, pp. 1-9. 
a)
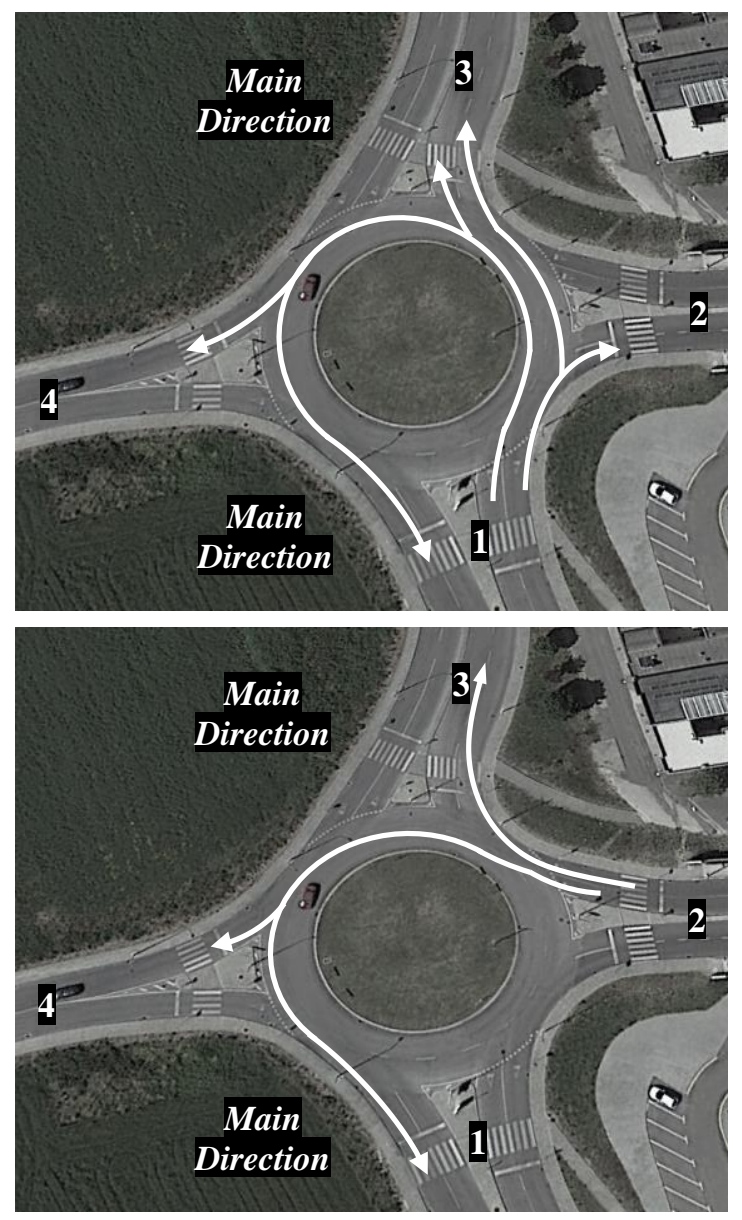

b)
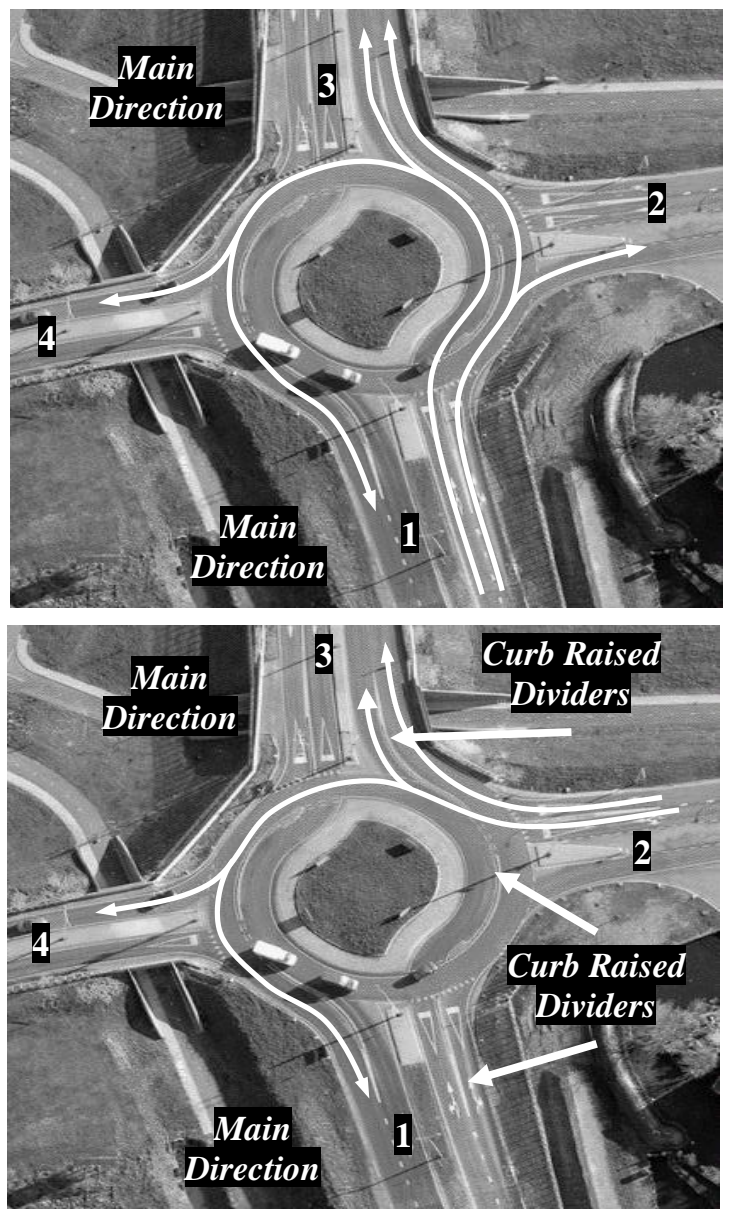

FIGURE 6 Differences between roundabout layouts: a) Conventional Two-lane roundabout; b) Basic Turbo-roundabout (3) [Source https://www.google.pt/maps]. 

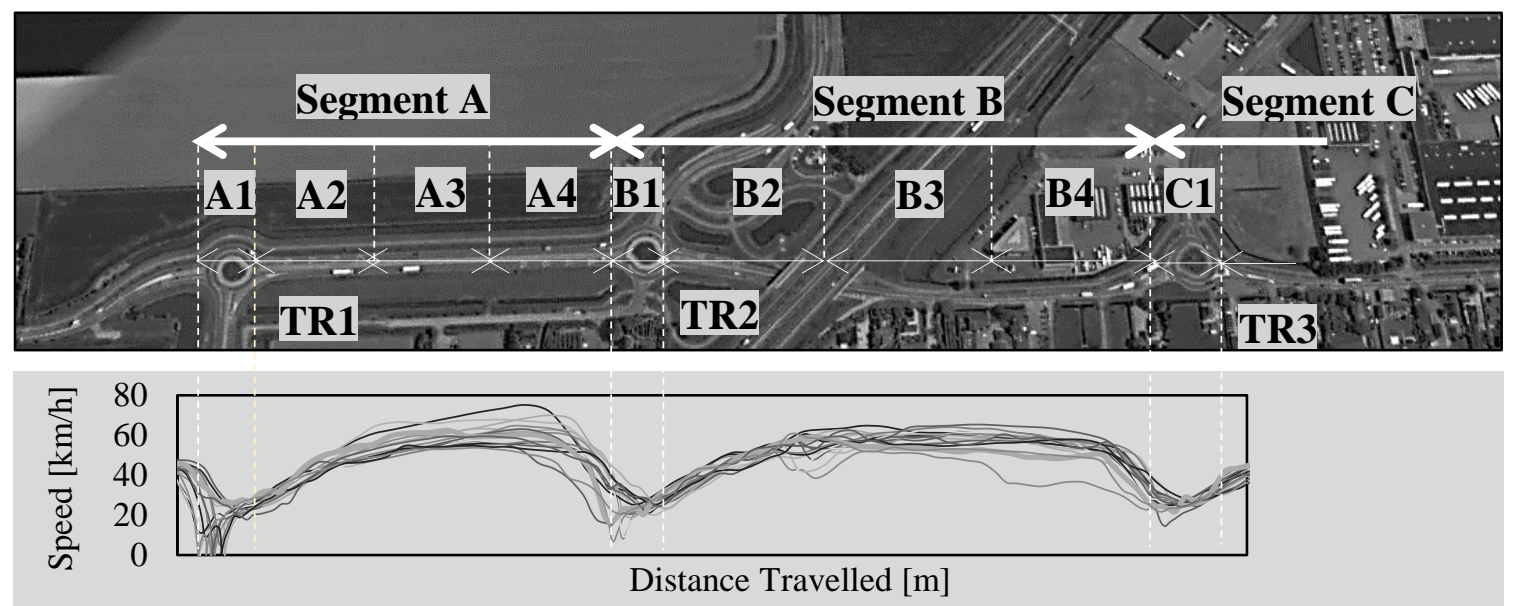

Legend: A1: Circulating Area of segment A; A2: Downstream of segment A; A3: Midblock of segment A; A4: Upstream of segment A; B1: Circulating Area of segment B; B2: Downstream of segment B; B3: Midblock of segment B; B4: Upstream of segment B; C1: Circulating Area of segment C; C2: Downstream of segment C

FIGURE 7 Segments and sub-segments definition for a corridor with turbo-roundabouts [Source https://www.google.pt/maps]. 
a)

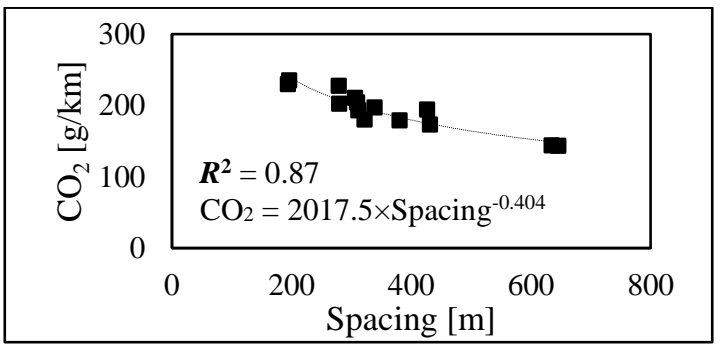

c)

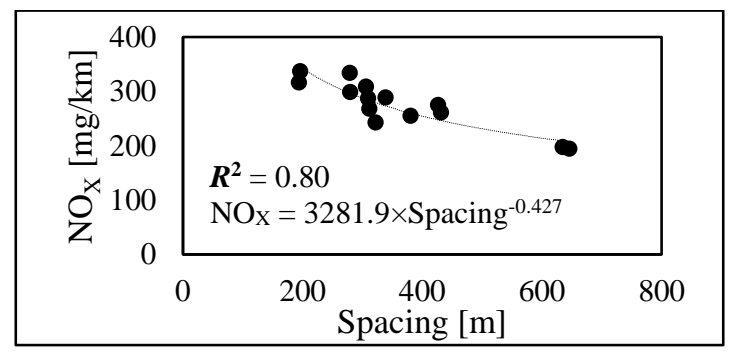

b)

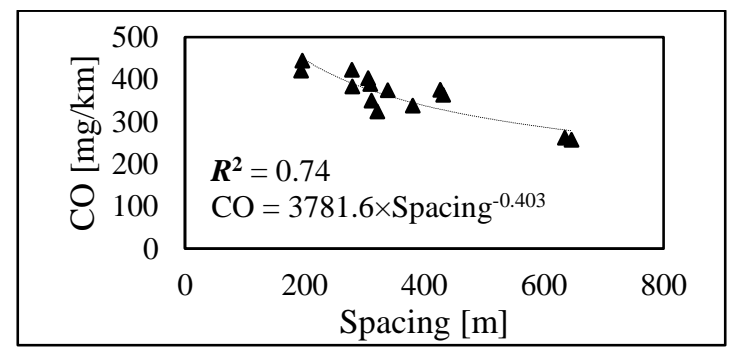

d)

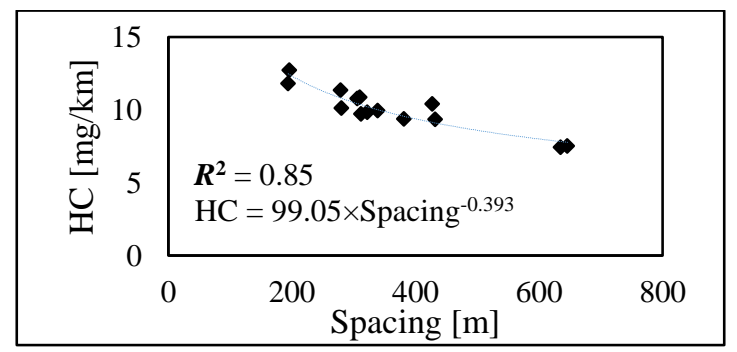

Note: Analysis of $R^{2}(F$-test) and model coefficients (T-test) resulted in p-values below 0.001 for all pollutants.

FIGURE 8 Emissions per kilometer versus spacing: a) $\mathrm{CO}_{2}$; b) $\mathrm{CO}$; c) $\mathrm{NOx}$; d) $\mathrm{HC}$. 
a)

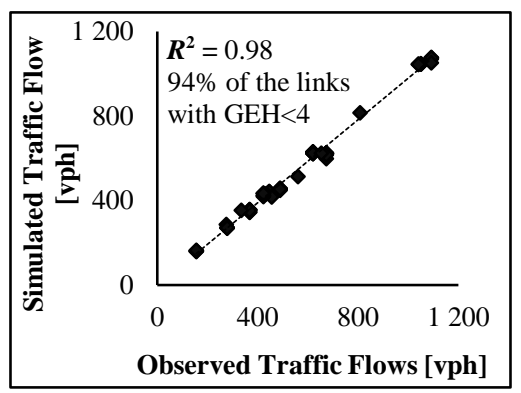

b)

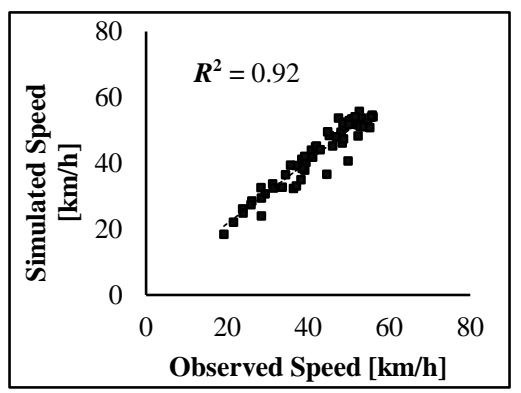

c)

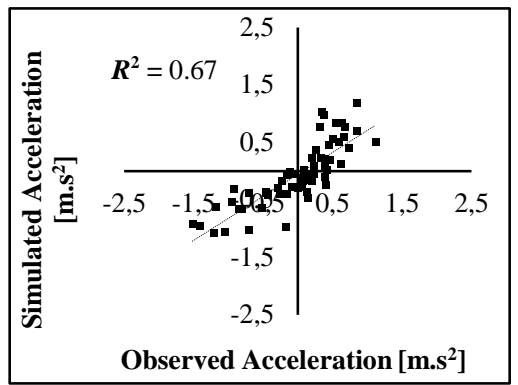

Car following - Average standstill distance (m): 0.85 Additive safety distance: 0.8 Multiple part of safety distance: 0.9 Gap acceptance - Front Gap: 0.25 s; Rear Gap: 0.25 s; Safety Distance Factor: 1.0

d)

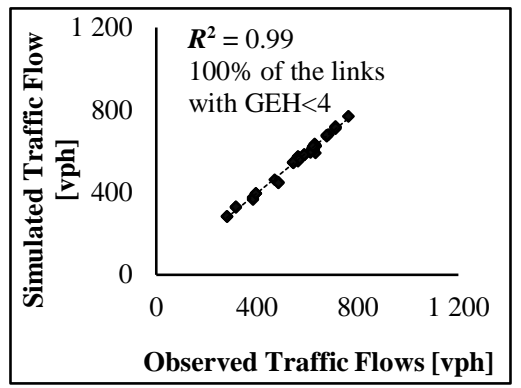

e)

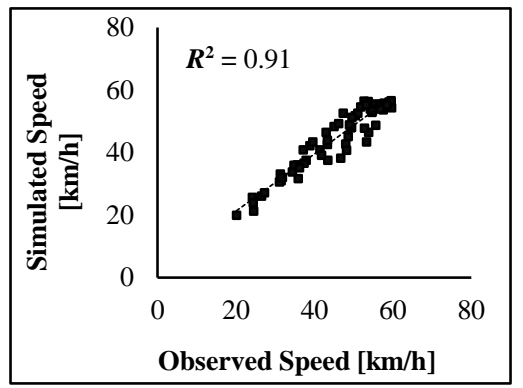

f)

Car following - Average standstill distance (m): 0.9 Additive safety distance: 1.0 Multiple part of safety distance: 1.0 Gap acceptance - Front Gap: 0.3 s; Rear Gap: 0.3 s; Safety Distance Factor: 1.0

g)

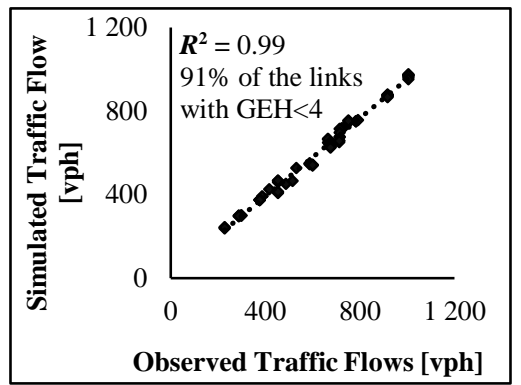

h)

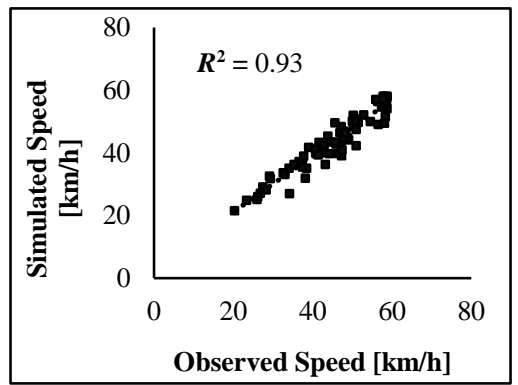

i)

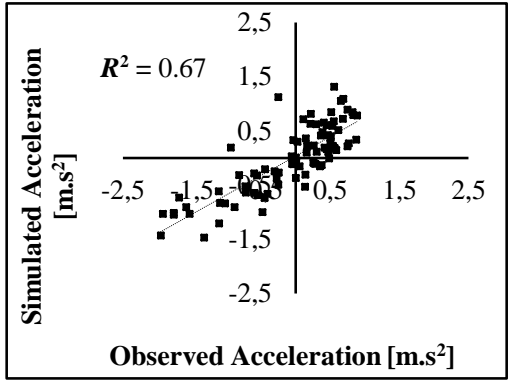

Car following - Average standstill distance (m): 0.85 Additive safety distance: 0.9 Multiple part of safety distance: 0.9 Gap acceptance - Front Gap: 0.3 s; Rear Gap: 0.3 s; Safety Distance Factor: 1.0

FIGURE 9 Observed versus Simulated parameters using calibrated model: a) N1-Volumes; b) N1-Speed; c) N1- Acceleration-Deceleration; d) N2-Volumes; e) N2-Speed; f) N2Acceleration-Deceleration; g) N3-Volumes; h) N3- Speed; i) N3- Acceleration-Deceleration. 
a)

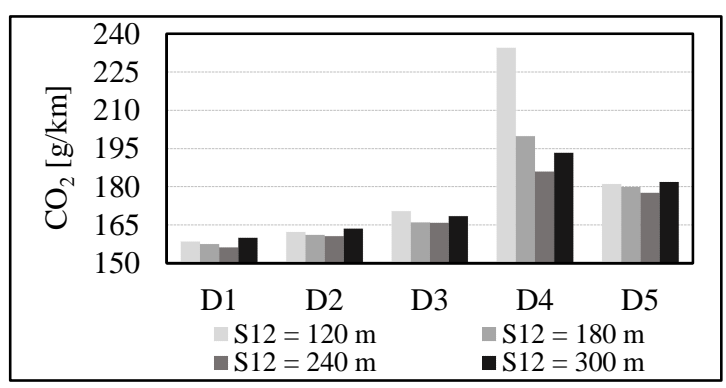

c)

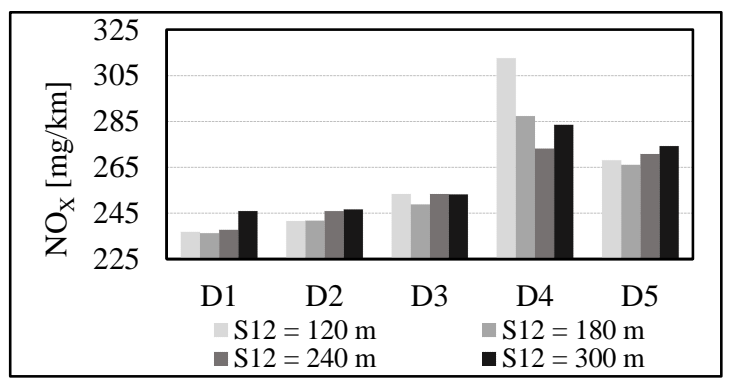

b)

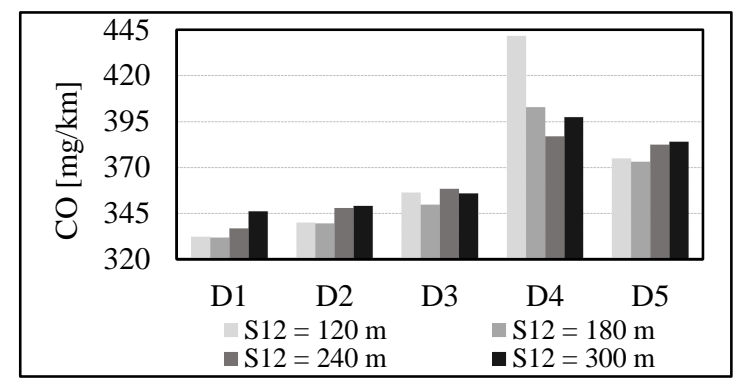

d)

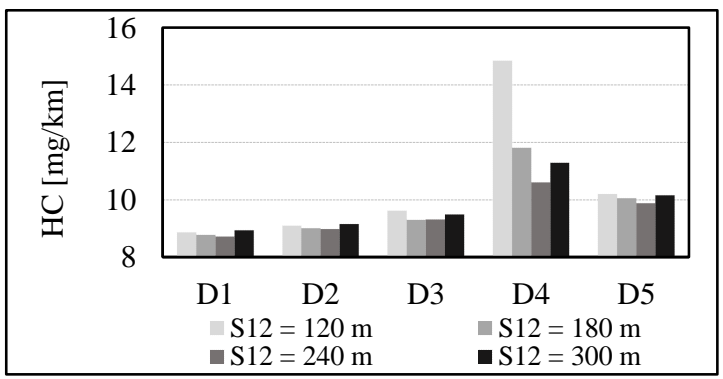

Legend: S12: Distance from the downstream exit lane of TR1 to the upstream yield lane of TR2

FIGURE 10 Emission trends with demand and spacing scenarios: a) $\mathrm{CO}_{2}$ per kilometer; b) CO per kilometer; c) NOx per kilometer; d) HC per kilometer. 
TABLE 4 Summary of Study Site Characteristics

\begin{tabular}{|c|c|c|c|c|c|c|c|c|}
\hline \multirow{2}{*}{$\begin{array}{l}\text { Site } \\
\text { ID }\end{array}$} & \multirow{2}{*}{$\begin{array}{c}\text { Turbo } \\
\text { RBT } \\
\text { ID }\end{array}$} & \multirow{2}{*}{$\begin{array}{l}\text { Layout } \\
\text { (21) }\end{array}$} & \multirow{2}{*}{$\begin{array}{c}\text { GPS } \\
\text { Coordinates }\end{array}$} & \multicolumn{2}{|c|}{ Traffic [vph] } & \multirow{2}{*}{$\begin{array}{c}\text { Distance from } \\
\text { upstream } \\
\text { roundabout }[\mathrm{m}]\end{array}$} & \multirow{2}{*}{$\begin{array}{c}\text { Average } \\
\text { Spacing } \\
{[\mathrm{m}]}\end{array}$} & \multirow{2}{*}{$\begin{array}{c}\text { Length of } \\
\text { the corridor } \\
{[\mathrm{m}]}\end{array}$} \\
\hline & & & & Arterial $^{\mathbf{a}}$ & $\begin{array}{l}\text { Side } \\
\text { Legs }\end{array}$ & & & \\
\hline \multirow{3}{*}{ N1 } & TR1 & Knee & $\begin{array}{c}52^{\circ} 11^{\prime} 23.05 " \mathrm{~N} \\
4^{\circ} 36^{\prime} 42.79 " \mathrm{E}\end{array}$ & & & & \multirow{3}{*}{$\begin{array}{c}375 \\
(0.28)^{\mathrm{b}}\end{array}$} & \multirow{3}{*}{1,300} \\
\hline & TR2 & Egg & $\begin{array}{c}52^{\circ} 1^{\prime} 15.12^{\prime \prime} \mathrm{N} \\
4^{\circ} 36^{\prime} 55.95 " \mathrm{E}\end{array}$ & 540 & 300 & 300 & & \\
\hline & TR3 & Partial & $\begin{array}{l}52^{\circ} 1 ' 3.83^{\prime \prime N} \\
4^{\circ} 37^{\prime} 12.55^{\prime \prime} \mathrm{E} \\
\end{array}$ & 635 & 450 & 450 & & \\
\hline \multirow{3}{*}{ N2 } & TR1 & Partial & $\begin{array}{c}51^{\circ} 59^{\prime} 13.56 " \mathrm{~N} \\
4^{\circ} 29^{\prime} 2.26 " \mathrm{E}\end{array}$ & & & & \multirow{3}{*}{$\begin{array}{c}473 \\
(0.53)^{\mathrm{b}}\end{array}$} & \multirow{3}{*}{1,400} \\
\hline & TR2 & Egg & $\begin{array}{c}51^{\circ} 58^{\prime} 59.42^{\prime \prime} \mathrm{N} \\
4^{\circ} 29^{\prime} 30.32 " \mathrm{E}\end{array}$ & 595 & 650 & 650 & & \\
\hline & TR3 & Basic & $\begin{array}{c}51^{\circ} 58^{\prime} 51.25^{\prime \prime} \mathrm{N} \\
4^{\circ} 29^{\prime} 42.79^{\prime \prime} \mathrm{E} \\
\end{array}$ & 650 & 295 & 295 & & \\
\hline \multirow{4}{*}{ N3 } & TR1 & Basic & $\begin{array}{c}52^{\circ} 9^{\prime} 40.38^{\prime \prime N} \\
4^{\circ} 32^{\prime} 57.47 " \mathrm{E}\end{array}$ & & & & \multirow{4}{*}{$\begin{array}{c}260 \\
(0.26)^{\mathrm{b}}\end{array}$} & \multirow{4}{*}{1,400} \\
\hline & TR2 & Basic & $\begin{array}{c}52^{\circ} 9^{\prime} 45.85 " \mathrm{~N} \\
4^{\circ} 33^{\prime} 4.83^{\prime \prime} \mathrm{E}\end{array}$ & 360 & 180 & 180 & & \\
\hline & TR3 & Egg & $\begin{array}{c}52^{\circ} 9^{\prime} 51.37^{\prime \prime} \mathrm{N} \\
4^{\circ} 33^{\prime} 24.42^{\prime \prime} \mathrm{E}\end{array}$ & 470 & 340 & 340 & & \\
\hline & TR4 & Partial & $\begin{array}{c}52^{\circ} 9^{\prime} 43.99 " \mathrm{~N} \\
4^{\circ} 33^{\prime} 38.42^{\prime \prime} \mathrm{E}\end{array}$ & 365 & 260 & 260 & & \\
\hline
\end{tabular}

Note: $\quad$ a) From data provided by Dutch authorities (values by road lane);

b) Coefficient of Variation (Standard Deviation of Spacing/Average Spacing).

Legend: RBT: Roundabout

Knee turbo-roundabout: has right-turn bypass lanes in one or more entries;

Egg turbo-roundabout: the number of lanes in the side legs differs from that on the turbo-roundabout itself (typically these legs are single-lane);

Partial turbo-roundabouts: has one lane for through traffic at least in one of the movements. 
TABLE 5 Emissions per vehicle and per kilometer by segment across turbo-roundabout corridor

\begin{tabular}{|c|c|c|c|c|c|c|c|c|c|c|c|c|}
\hline Site & Pollutant & CA & D & $\mathbf{M}$ & $\mathbf{U}$ & Total & Pollutant & $\mathbf{C A}$ & D & $\mathbf{M}$ & $\mathbf{U}$ & Average \\
\hline \multirow{4}{*}{ N1 } & $\mathrm{CO}_{2}[\mathrm{~g}]$ & 32 & 53 & 41 & 25 & 151 & $\mathrm{CO}_{2}[\mathrm{~g} / \mathrm{km}]$ & 207 & 245 & 147 & 93 & 173 \\
\hline & $\mathrm{CO}[\mathrm{mg}]$ & 56 & 113 & 79 & 48 & 296 & $\mathrm{CO}[\mathrm{mg} / \mathrm{km}]$ & 362 & 542 & 284 & 168 & 339 \\
\hline & NOx [mg] & 40 & 87 & 61 & 29 & 217 & NOx $[\mathrm{mg} / \mathrm{km}]$ & 256 & 419 & 220 & 101 & 249 \\
\hline & HC [mg] & 1.8 & 2.7 & 1.8 & 1.8 & 8.1 & HC [mg/km] & 11.8 & 11.7 & 7.2 & 6.3 & 9.2 \\
\hline \multirow{4}{*}{$\mathbf{N} 2$} & $\mathrm{CO}_{2}[\mathrm{~g}]$ & 27 & 66 & 43 & 25 & 161 & $\mathrm{CO}_{2}[\mathrm{~g} / \mathrm{km}]$ & 194 & 219 & 120 & 89 & 155 \\
\hline & $\mathrm{CO}$ [mg] & 47 & 123 & 76 & 45 & 291 & $\mathrm{CO}[\mathrm{mg} / \mathrm{km}]$ & 339 & 407 & 212 & 158 & 279 \\
\hline & NOx $[\mathrm{mg}]$ & 33 & 102 & 57 & 27 & 219 & NOx $[\mathrm{mg} / \mathrm{km}]$ & 235 & 336 & 159 & 95 & 206 \\
\hline & HC [mg] & 1.8 & 2.7 & 1.8 & 1.8 & 8.1 & HC [mg/km] & 10.8 & 9.9 & 6.3 & 6.3 & 8.3 \\
\hline \multirow{4}{*}{ N3 } & $\mathrm{CO}_{2}[\mathrm{~g}]$ & 53 & 63 & 51 & 20 & 187 & $\mathrm{CO}_{2}[\mathrm{~g} / \mathrm{km}]$ & 204 & 222 & 165 & 78 & 167 \\
\hline & $\mathrm{CO}[\mathrm{mg}]$ & 99 & 123 & 91 & 35 & 347 & $\mathrm{CO}[\mathrm{mg} / \mathrm{km}]$ & 369 & 433 & 282 & 142 & 304 \\
\hline & NOx [mg] & 80 & 95 & 68 & 19 & 262 & NOx [mg/km] & 284 & 342 & 223 & 77 & 232 \\
\hline & HC [mg] & 2.7 & 2.7 & 1.8 & 1.8 & 9.0 & HC [mg/km] & 10.8 & 9.9 & 7.2 & 6.3 & 8.6 \\
\hline
\end{tabular}

Legend: CA: Circulating Area; D: Downstream; M: Midblock; U: Upstream; Red cells indicate the highest value 
TABLE 6 Emissions and traffic performance parameters (with standard error of the mean) per scenario

\begin{tabular}{|c|c|c|c|c|c|c|c|}
\hline \multirow{2}{*}{$\begin{array}{l}\text { Site } \\
\text { ID }\end{array}$} & \multirow{2}{*}{$\begin{array}{c}\text { Corridor } \\
\text { Layout }\end{array}$} & \multicolumn{4}{|c|}{ Emissions } & \multicolumn{2}{|c|}{ Traffic Performance } \\
\hline & & $\mathrm{CO}_{2}[\mathrm{~kg}]$ & $\mathrm{CO}[\mathrm{g}]$ & NOx $[g]$ & $\mathrm{HC}[\mathrm{g}]$ & $\begin{array}{c}\text { Travel Time } \\
\text { [s/veh] }\end{array}$ & $\begin{array}{c}\text { Total } \\
\text { Stops }\end{array}$ \\
\hline \multirow{2}{*}{ N1 } & Turbo & $374(2.7)$ & $913(9.2)$ & $1,220(25.1)$ & $65.4(1.6)$ & $77.2(0.2)$ & $495(15.3)$ \\
\hline & Conventional & $373(2.3)$ & $908(7.0)$ & $1,219(19.3)$ & $65.3(1.2)$ & $75.9(0.2)$ & $513(10.9)$ \\
\hline \multirow{2}{*}{$\mathbf{N 2}$} & Turbo & $254(1.7)$ & $542(3.4)$ & $383(2.5)$ & $14.0(0.1)$ & $70.9(0.4)$ & $353(8.4)$ \\
\hline & Conventional & 247 (1.6) & $530(3.2)$ & $376(2.7)$ & $13.5(0.2)$ & $68.4(0.5)$ & $303(8.9)$ \\
\hline \multirow{2}{*}{ N3 } & Turbo & $356(2.5)$ & 747 (5.2) & $534(3.7)$ & $19.8(0.1)$ & $82.4(0.1)$ & $295(8.0)$ \\
\hline & Conventional & $353(2.7)$ & $739(5.5)$ & $530(4.0)$ & $19.0(0.2)$ & $80.0(0.3)$ & $283(10.3)$ \\
\hline
\end{tabular}

Note: Average values using 15 random seed runs

Legend: Shadow cells indicate that the difference between conventional and turbo-roundabout output measure was not statistically significant $(p$-value $<0.05)$ 